\title{
THE INTENSIFICATION OF THE OUTER SUBURBS AND THE IMPACT ON TRAVEL BEHAVIOUR: AN ANALYSIS OF YORK REGION
}

$$
\text { by }
$$

\author{
Paul Grove \\ HBA, University of Toronto, 2013 \\ A Major Research Paper \\ presented to Ryerson University \\ in partial fulfillment of the requirements for the degree of \\ Master of Planning \\ in \\ Urban Development
}

Toronto, Ontario, Canada, 2015

(C) Paul Grove, 2015 


\section{AUTHOR'S DECLARATION FOR ELECTRONIC SUBMISSION OF A MRP}

I hereby declare that I am the sole author of this MRP. This is a true copy of the MRP, including any required final revisions.

I authorize Ryerson University to lend this MRP to other institutions or individuals for the purpose of scholarly research.

I further authorize Ryerson University to reproduce this MRP by photocopying or by other means, in total or in part, at the request of other institutions or individuals for the purpose of scholarly research.

I understand that my MRP may be made electronically available to the public. 


\title{
THE INTENSIFICATION OF THE OUTER SUBURBS AND THE IMPACT ON TRAVEL BEHAVIOUR: AN ANALYSIS OF YORK REGION
}

\author{
(C) Paul Grove, 2015 \\ Master of Planning \\ in \\ Urban Development \\ Ryerson University
}

\begin{abstract}
In an effort to retrofit outer suburban municipalities to be more supportive of public transit, and less oriented toward private auto, intensification is being practiced throughout the Greater Golden Horseshoe. York Region, an outer suburban municipality undergoing intensification, has been selected for analysis. This report studies TTS (Transportation Tomorrow Survey) data using multiple linear regression, as well as comparative analysis to evaluate the effect an increase in density has upon transit modal split. Findings align strongly with reviewed literature. Findings are that while density and transit mode split are positively statistically correlated, the impact density is estimated to have on transit mode split is minimal. This suggests intensifying the outer suburbs may have the reverse effect of increasing auto traffic at the expense of small increases in transit mode split. A series of recommendations regarding transportation policies for outer suburban municipalities are then provided to coexist with intensification policies.
\end{abstract}

Key words: smart-growth, intensification, outer suburbs, public transit, travel behaviour 


\section{Table of Contents}

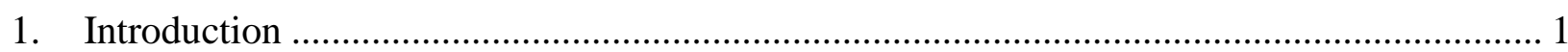

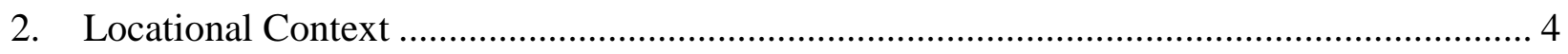

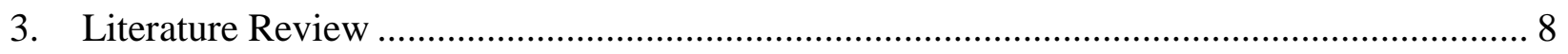

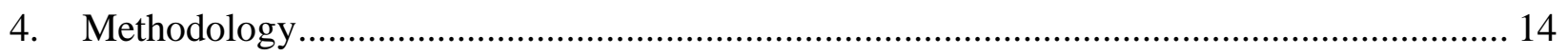

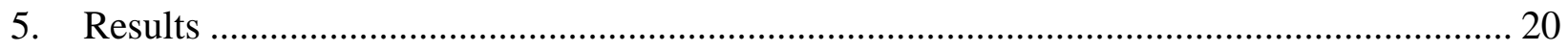

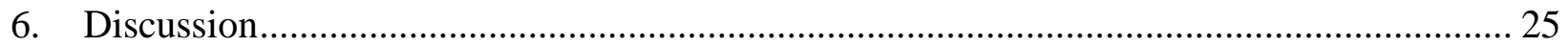

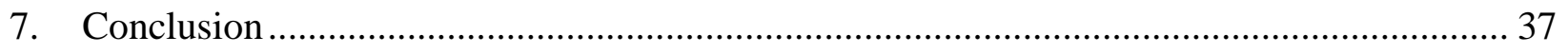

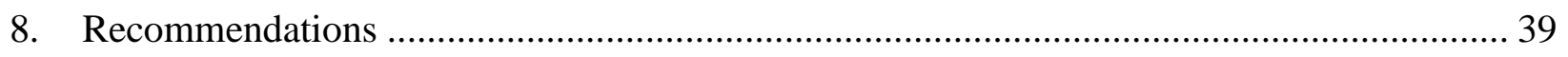

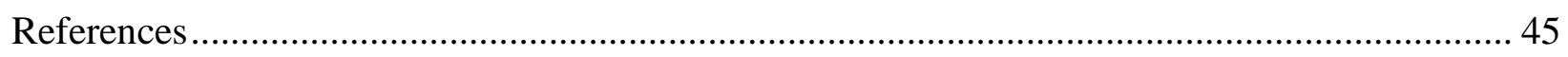




\section{List of Tables}

Table 1: York Region Lower-Tier Municipality Density and \% Single-Detached Homes (2011) 6

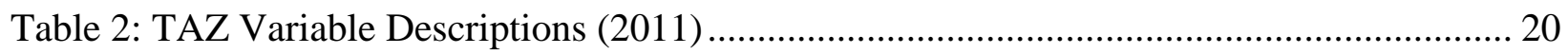

Table 3: TAZ Regression Results (2011) .................................................................... 21

Table 4: York Region Average Density and Mode Split Change Scenario (2011) ................... 29

Table 5: York Region Density-Transit Relationship Comparison $(2006$ - 2011) ..................... 30

Table 6: York Region Density Increase-Transit Change Relationship (2006 - 2011) .............. 31 


\section{List of Figures}

Figure 1: The Regional Municipality of York (York Region) .............................................. 4

Figure 2: York Region TAZs Used for Analysis ........................................................... 16

Figure 3: 2011 York Region Density (People per sq. km.) .................................................. 26

Figure 4: 2011 York Region Transit Mode Split $(\%)$........................................................ 27

Figure 5: 2006 - 2011 York Region Change in Density (People per sq. km.) ......................... 33

Figure 6: 2006 - 2011 York Region Transit Mode Split Change (\%)................................... 34 


\section{Introduction}

Significant change in the built environment continues to occur as a stronger focus becomes placed on increasing the density of suburban locations. This focus on increasing density is being placed upon locations and areas which are not typically inhabited or designed for supporting higher densities, such as outer suburban locations. As per the Growth Plan for the Greater Golden Horseshoe (Growth Plan), as well as the Provincial Policy Statement 2014 (PPS), it is made an important goal and urban planning strategy that areas deemed most appropriate to support higher densities should experience an increase in density. This has been termed intensification, which can be considered a smart-growth policy.

In the hopes of creating more efficient places to live in terms of transportation, intensification is promoted as reducing the reliance upon private auto. This is accomplished through the clustering of activities as density increases, allowing for shorter travel distances between origins and destination, or more effective public transit servicing between relatively higher density nodes. The Growth Plan requires that by $2015,40 \%$ of all residential growth is to by means of intensification in the province of Ontario. This is a considerable amount of growth that will be required to occur in municipalities that were not originally intended to support high density growth. This is not to diminish the benefit intensification can provide in terms of supporting public transit. However, an increase in density alone may not necessarily result in an increase in public transit ridership, or a considerable alteration of travel behaviour. Rather, increasing density in areas not capable of supporting such, or in areas where travel behaviour is auto dependent, may lead to an increase in traffic volumes, working counter-productively toward achieving the goals of intensification. 
To evaluate the transportation impacts intensification is having upon outer suburban locations, a selected regional municipality in the Greater Toronto Hamilton Area (GTHA) will be studied. This is the Regional Municipality of York (York Region). The GTHA is a diverse area in terms of its built form, with numerous communities in its suburbs and outer suburbs experiencing intensification rather recently. Particular suburban and outer suburban areas that have experienced intensification include North York Centre, communities along the Sheppard Street corridor, the Highway 7 corridor in Markham, the Centre Street corridor in Vaughan, Scarborough City Centre, and Richmond Hill Centre. A number of these communities are located within the outer suburban municipality of York Region. This means York Region provides an opportunity to evaluate the effect an increase in density is having on transportation behaviour in the outer suburbs. Transportation Tomorrow Survey (TTS) secondary data will be used to compare modal split and travel characteristics of York Region in the most recent survey year of 2011. This will provide a quantitative overview of how travel behaviour in an outer suburban region is affected by increasing density in the outer suburban GTHA.

Studying the transit and density relationship is an important and timely topic to investigate in an outer suburban context. Many communities in York Region have begun to intensify to densities much greater than their surroundings, including centres such as Vaughan Metropolitan Centre, Markham Centre, and Richmond Hill Centre. These are areas and municipalities that have not previously experienced significant density increases, and the subsequent impact on travel behaviour is not necessarily well known. Before intensification is applied and practiced on a large scale, such as in the previously mentioned centres, it should be understood what the anticipated change in travel behaviour will be. If a drastic increase in density does not result in a significant increase in transit usage, or alteration in travel behaviour, 
the result may be worsening issues of auto congestion, further impeded travel times, and local degradation of air quality, and road safety. This has been indicated by those such as Melia, Parkhurst, Barton (2011), as well as Gordon, Richardson (2001). This result would be counterproductive toward achieving the benefits intensification is considered to provide, and potentially complicate existing traffic patterns and travel behaviour. 


\section{Locational Context}

To understand the impacts of density or intensification on mode choice in a suburban context, York Region has been studied. York Region is located immediately north of the City of Toronto, bordering Durham Region to its east, Peel Region to its west, and Simcoe Country to its north. A map of the Region is provided in Figure 1. York Region is an upper-tier municipality containing nine lower-tier municipalities including Aurora, East Gwillimbury, Georgina, King,

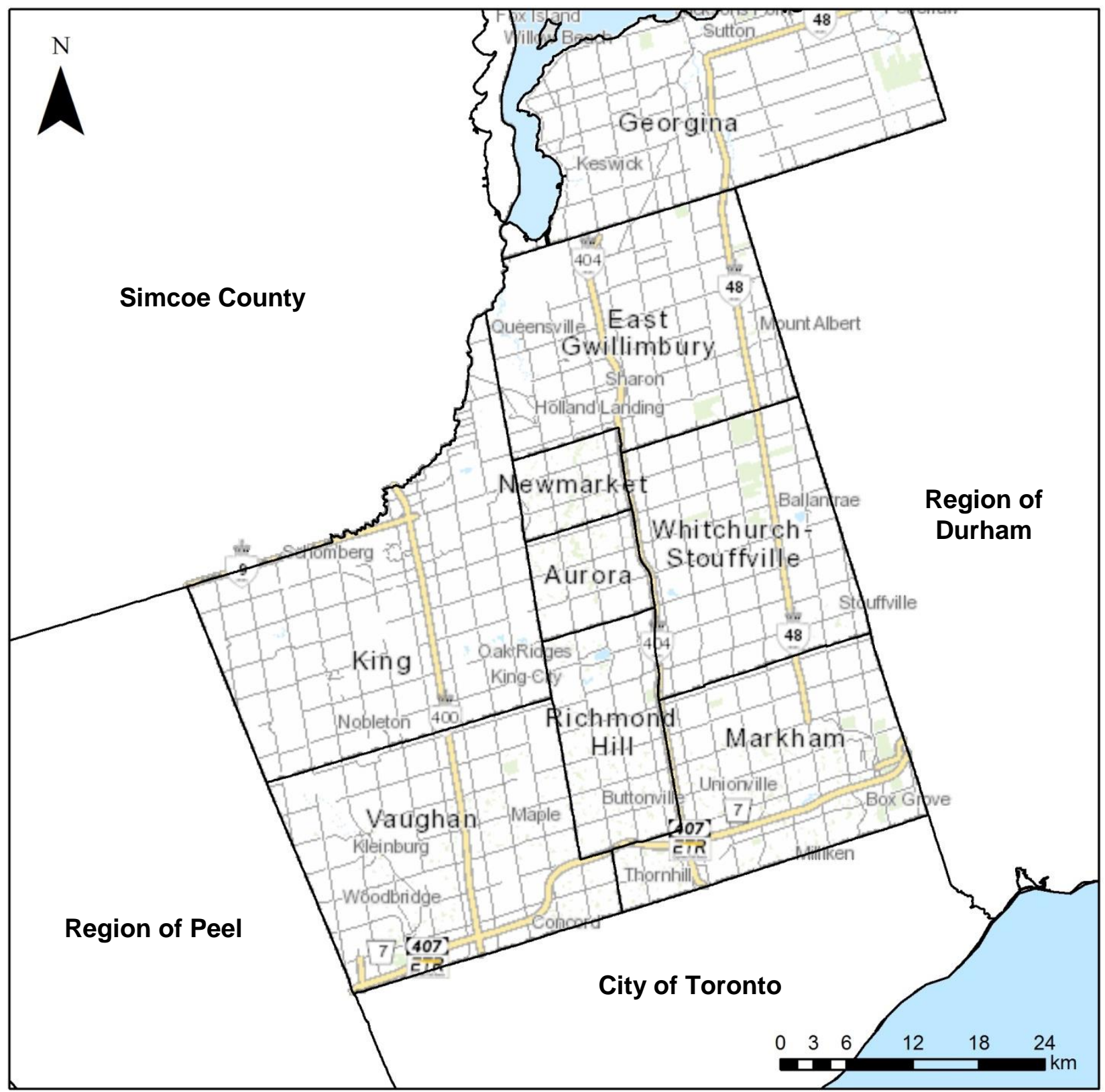

Figure 1: The Regional Municipality of York (York Region) 
Markham, Newmarket, Richmond Hill, Vaughan, and Whitchurch-Stouffville. These nine municipalities all differ quite substantially in terms of their built form, population density, and transit accessibility and mobility. However, these differences allow for various factors influencing mode choice in an outer suburban context to be apparent in addition to the influence of density.

York Region is a rapidly growing municipality. York Region's population as of 2011 was approximately 1,032,524 people (Statistics Canada, 2013). This was an increase of approximately 139,812 people since 2006, or a change in population of $15.7 \%$ (Statistics Canada, 2013). York Region is expected to continue its rapid growth. As per the Growth Plan, $40 \%$ of all new residential growth will be by means of intensification starting in 2015 . Therefore, a significant portion of York Region's continued growth will be supported by relatively higher density built form. Referring to growth targets set by the Growth Plan, York Region is expected to have its population grow to 1.5 million people by 2031 . This will occur alongside an employment growth from 700,000 jobs, to 780,000 jobs. This is a $15 \%$ population growth and an $11 \%$ employment growth for the Region. More locally, the City of Vaughan for example, within its Vaughan Metropolitan Centre Secondary Plan, has forecasted a population of 25,000 people with the availability of 11,500 new jobs. These targets are to satisfy the Growth Plan's density target of 200 persons per hectare. Therefore, York Region is anticipated to continue its high level of growth into the foreseeable future.

It was estimated in 2011 that York Region contains some 323,545 households, 215,725 of which are single-detached homes (Statistics Canada, 2013). This is equivalent to 67\% of York Region households being in the form of single-detached homes, compared to the City of Toronto which in 2011 was estimated to have $26 \%$ of its household share as single-detached homes 
(Statistics Canada, 2013). York Region is as a result, a dominantly suburban regional municipality. The overall population density of York Region per square kilometre was estimated to be approximately 585.9 in 2011 . This is compared to the City of Toronto's overall density of 4,149.5 in 2011 (Statistics Canada, 2013). However, built form does vary amongst the Region's lower-tier municipalities. The percentage of single-detached homes as well population density for each of the nine municipalities is displayed in Table $\mathbf{1 .}$

Table 1: York Region Lower-Tier Municipality Density and \% Single-Detached Homes (2011)

\begin{tabular}{lccc}
\hline Municipality & Population & $\begin{array}{c}\text { \% Single-Detached } \\
\text { Homes }\end{array}$ & $\begin{array}{c}\text { Population Density } \\
\text { (per sq. } \mathrm{km})\end{array}$ \\
\hline Newmarket & 79,978 & $59 \%$ & $2,086.3$ \\
Richmond Hill & 185,541 & $62 \%$ & $1,838.0$ \\
Markham & 301,709 & $64 \%$ & $1,419.3$ \\
Aurora & 53,203 & $62 \%$ & $1,068.8$ \\
Vaughan & 288,301 & $68 \%$ & $1,054.0$ \\
Whitchurch-Stouffville & 37,628 & $79 \%$ & 182.3 \\
Georgina & 43,517 & $83 \%$ & 151.2 \\
East Gwillimbury & 22,473 & $84 \%$ & 91.7 \\
King & 19,899 & $92 \%$ & 59.7 \\
\hline
\end{tabular}

Generally, the more southern municipalities, or municipalities located along major corridors (Vaughan, Markham, Richmond Hill, Newmarket), are the more populous municipalities, featuring higher population densities. This is largely due to York Region land-use planning. York Region has planned for higher population densities to exist along or within what have been termed "Centres" and "Corridors". These "Centres" and "Corridors" are located along major arterial roads that are serviced by York Region Transit's (YRT) VIVA Rapid Transit routes. These routes include VIVA Purple or Pink, which operate along the Highway 7 corridor, or VIVA Blue which operates along Yonge Street. Furthermore, the "Centres" tend to be areas that are located nearby a transit hub or terminal, or the historic centres of the municipalities. The "Centres" include Vaughan Metropolitan Centre, Markham Centre, Richmond Hill/Langstaff 
Gateway, and Newmarket Centre. These areas all are planned to, or currently feature higher density development, such as mid-rise condominiums, and office buildings. They differ, or are planned to differ in their built form rather drastically in comparison to all other areas of York Region, which are generally low-density suburban communities, employment areas, or undeveloped areas. York Region has, therefore, planned for intensification somewhat extensively, and will continue doing so throughout its "Centres" and "Corridors".

As for transit service itself in York Region, currently, and during the study year of 2011, YRT provides services as both local transit routes, and rapid transit routes. The rapid transit routes are operated by VIVA along the major corridors, or routes in high demand. The demand for the YRT system has been increasing over time, with approximately 7.7 million annual riders observed in 2001, and approximately 19.4 million annual riders observed in 2011 (York Region Transit, 2011). More recently, the YRT system has begun undergoing service improvements by means of dedicated bus lanes, or bus-rapid-transit (BRT) service along the Region's major corridors. These service improvements rely strongly on the intensification of the immediately surrounding areas. This is evident through the Region's Official Plan - 2010. Placed into policy is the strategy that by constructing BRT routes along or within higher density areas, transit mode split will increase, and general transportation improvements will result. General transportation improvements include less auto congestion on the road network, and other external improvements including improved air quality, and road safety. In order for this to occur, however, density increases in the outer suburban context of York Region will need to have a significant positive effect on transit usage. 


\section{Literature Review}

The purpose of this study is to identify if density has a considerable positive influence on travel behaviour in an outer suburban context. This is considered to be important as a result of the intensification policies directed to municipalities in Ontario. The travel behaviour hoped to be observed is that as density increases in outer suburban areas, auto usage will decrease and transit usage will increase. A considerable amount of research has been performed in the existing literature on the topic of density and auto dependency. As a result, there are significant findings that density and urban form does have an influence on travel behaviour. This research, however, has not been conducted to a large extent on outer suburban locations that are in the process of, or have recently increased in density. On the contrary, there also exists a significant amount of literature that discredits intensification or densification as a means of facilitating less reliance on private auto. Furthermore, this body of literature argues that intensification may even serve to create the opposite of the desired effect. Finally, some literature does discuss the importance of having complimentary policy alongside a density increase policy in order to effectively influence a reduction in private auto usage. These three literature themes will be discussed separately.

Research within the existing literature has shown density can have an impact on mode choice by decreasing private auto usage. This has largely been shown through the use of regression models (Melia, 2010; Jun, 2008; Vance, Hedel, 2007; Susilo, Maat, 2007; Schwanen, Dijst, Dieleman, 2004). These models were created for context specific areas of study. They included variables related to population demographics, transportation factors, and built form factors. Schwanen, Dijst, Dieleman (2004) found built form variables to be statistically significant in impacting mode choice in cities in the Netherlands. These variables included primarily land-use mix, street connectivity, and residential density. An increase in any of these 
variables was found to result in an increase in either active transportation or public transit usage. As for suburban areas in the Netherlands, built form factors have been found to be increasingly impactful over-time (Susilo, Maat, 2007). In a North American example, research conducted in smart-growth communities in Portland revealed that built form factors were statistically significant in influencing mode choice as well (Jun, 2008). These built form factors are similar to those found in the Netherlands (Susilo, Maat, 2007; Schwanen, Dijst, Dieleman, 2004) being residential density, employment density, land-use mix, and distance to a transit stop.

Often a concern with determining causes of travel behaviour, such as built form factors, is the issue of self-selection. This is the argument that those who want to travel a certain way will locate in areas where their preferences can be met, therefore eliminating causality from any statistical findings. Vance, Hedel (2007) in a second performed test using a model built to account for self-selection bias found that built form variables were still found to be statistically significant in increasing transit mode split. Overall, there exist significant findings in the literature to suggest that higher residential density does result in increased transit mode split.

However, of the reviewed literature demonstrating a link between density and reduced auto usage, additional findings that provide alternative perspectives on travel behaviour are worth noting. Of these findings, demographics and transportation factors are concluded to have a much stronger impact on mode choice versus built form variables (Jun, 2008; Susilo, Maat, 2007; Schwanen, Dijst, Dieleman, 2004). Indeed, in the existing literature the most commonly reported variables impacting mode choice were found to be access to a car, travel distance, income, and household size (Jun, 2008; Susilo, Maat, 2007; Schwanen, Dijst, Dieleman, 2004). This does indicate that increasing density may not have a large impact in influencing a change in travel behaviour. These findings, however, are not to discredit or ignore the statistically 
significant findings that suggest an increase in density does decrease auto usage. Of the literature reviewed, concluded is that density does play a role in influencing mode choice, but results are not overly convincing that density plays a large enough role in altering travel behaviour in a suburban context. Even so, while it is generally agreed that the built form of post-war suburbs is auto-oriented and not supportive of public transit, those such as Frisken, Wallace (2002) argue that suburban transit can work well if nodes of activities, or high density clusters are created. Suggested is that density is one factor among many that can alter travel behaviour.

While some of the literature appears to be in support of density having a positive influence on reducing private auto usage, there is also a portion of literature that opposes the notion that increases in density will alter modal split and travel behaviour away from private auto (Melia, Parkhurst, and Barton, 2010; Echenique, Homewood, 2003; Richardson, 2000; Mees, 1995). One of the central arguments on this side of the density travel behaviour debate is that post-war suburban neighbourhoods prevalent throughout North America, and parts of Europe, are not conducive to supporting transit. Their built form is simply incompatible. In the event that suburban municipalities densify by introducing centres, they are often too small to attract enough trips from a plethora of locations to make transit a mode choice that can compete with the convenience of private auto (Mees, 1995). Others such as Melia, Parkhurst, and Barton (2010), have argued that intensification is capable of increasing transit ridership. However, after reviewing the statistical changes often observed in transit usage as a result of increasing density, it was concluded that these changes are not sufficient to outweigh the increases in auto traffic that intensification causes. Therefore, intensification is found to defer some auto trips, but it is also found to create a much greater amount of additional auto traffic as a result of a large newly introduced population, therefore masking the anticipated travel behaviour alterations. This is not 
to say that the successful deferring of auto trips is not important. However, the increase in density needed to make transit viable introduces a considerable amount of new auto traffic.

At the extreme end of the argument against intensification and densifying to encourage alternate modes of travel such as public transportation, is the argument that intensification works against the goals it claims to help achieve (Echenique, Homewood, 2003; Richardson, 2000). The argument is a step beyond that of Melia, Parkhurst, and Barton (2010), which is that the newly introduced auto traffic in intensified areas outweighs the benefit observed from deferred auto trips. As a result of the increase in auto trips in areas that were previously lower density, auto congestion worsens, as do environmental factors associated with auto usage. This includes air quality, and noise pollution (Richardson, 2000). Furthermore, that as a result of increased auto congestion, costs associated with auto usage will also increase for residents or employees in these areas. These costs include fuel costs, and general maintenance (Echenique, Homewood, 2003).

A common criticism of lower density suburban areas is often that the residents of these areas tend to spend large amounts of time commuting to work. A 20 year review of travel times in suburban communities in the U.S. by Richardson (2000) revealed that commute times were not increasing despite increasing VMT (vehicle-miles-traveled). This, however, is a relatively older study. While an older study performed of commutes in the Washington D.C. area generally supports this conclusion (Levinson, Kumar, 1994), a revisit of these findings a decade later indicated that commute times in the Greater Washington Area were no longer remaining stable (Levinson, $\mathrm{Wu}, 2005)$. Nonetheless, it is argued that intensification will only worsen commute times, as auto traffic increases in areas that previously needed to support less auto traffic on the road network (Echenique, Homewood, 2003; Richardson, 2000). 
Despite the existence of literature that argues intensification results in many negative consequences, the literature does not disagree that density can have a statistical impact on travel behaviour. Generally, however, much of the literature does agree that an increase in density alone is not sufficient to result in any substantial change in travel behaviour that is desired in lower density areas (Cervero, King, 2010; Melia, Parkhurst, and Barton, 2010; Jun, 2008; Susilo, Maat, 2007). The two most discussed policies or strategies suggested to accompany intensification in the literature are parking, and transit policies or strategies. Indeed, transportation related factors within statistical regression models were found to have a much more profound impact on mode choice (Jun, 2008; Vance, Hedel, 2007; Susilo, Maat, 2007; Schwanen, Dijst, Dieleman, 2004).

Cervero, King (2010) provided findings of a study performed in neighbourhoods surrounding BRT (bus-rapid-transit) routes in Seoul. Found was that BRT service can be a highly influential factor in deferring auto trips, and that the type of transit provided in densifying areas is not as important as the quality of that transit. In order for a large uptake in transit trips to occur in areas more auto-oriented, and where the population is accustomed to using private auto, transit needs to provide advantages over private auto. Density changes alone are not sufficient to make auto usage disadvantageous enough in comparison to transit. While transit may be available in areas targeted for increased density, the service quality provided may not be enough to outweigh the many advantages auto usage provides over transit. On the contrary, however, Susilo, Maat (2007) found that while transit usage does increase in denser areas, accessibility of transit was not found to be profoundly impactful upon choosing a mode. This finding was attributed to high existing levels of auto ownership, and high average auto travel speeds. Parking strategies such as parking reductions were, therefore, recommended. This notion is supported by 
Schwanen, Dijst, Dieleman, (2004) as auto related factors were found to be most impactful on mode choice.

In summation, density may have an impact on mode choice. The extent of this impact, however, is likely limited when coupled with an increase in population in areas where the population is auto reliant. While density is a crucial factor in making transit a viable form of transportation, it alone does not result in a large change in travel behaviour. Intensification, therefore, requires other policies and/or strategies such as transit improvements, or parking standard reductions. The remainder of study will attempt to establish to what extent density in an outer suburban context of the GTHA affects mode choice. The hypothesis tested will be that, statistically, there is a noticeable change in mode choice as a result of density changes, but this affect is not significant enough to achieve many of the transportation goals envisioned for intensified areas. 


\section{Methodology}

The devised methodology is to test the hypothesis that an increase in density does have a statistical correlation with an increasing transit modal split in the outer suburban municipality of York Region. The devised methodology will also use other transportation factors such as vehicle ownership, or available parking at an individual's workplace to act as control variables. In the case that density is found to have a positive statistical correlation with transit mode split in York Region, the extent of this correlation will be evaluated. In other words, it will be evaluated whether or not an increase in density has a positive correlation with transit mode split, therefore, indicating that intensification results in increased transit mode split as well as changes in travel behaviour.

To test the hypothesis, multiple linear regression analysis will used. Multiple regression analysis will allow for a variety of control factors to be tested in addition to density to determine the existence of a statistical correlation with transit modal split. Much of the existing literature on determining correlation and causality between density and mode split uses various forms of multiple regression models (Jun, 2008; Vance, Hedel, 2007; Susilo, Maat, 2007; Schwanen, Dijst, and Dieleman, 2004). Multiple regression modelling allows testing for correlation while also serving a predictive purpose. That is, as one independent variable, or a set of independent variables increases or decreases, an expected increase or decrease in the dependent variable can be estimated. For the purposes of this study, a multiple regression analysis will predict how changes in density will affect changes in transit modal split.

Data are to be collected from the Transportation Tomorrow Survey (TTS). The TTS Survey is a joint survey undertaken by agencies represented as the Transportation Information Steering Committee (TISC). It is a comprehensive survey conducted to provide a broad set of 
data regarding transportation in the GTHA. This includes the municipalities of the City of Toronto, the City of Hamilton, and the regional municipalities of Durham Region, Halton Region, Peel Region, and York Region. However, surveyed areas also include much of the Greater Golden Horseshoe, such as the Niagara Peninsula, Simcoe County, Peterborough, and Kitchener-Waterloo.

TTS data are attributed to individually devised Traffic Area Zones (TAZs), which combined compose each of the surveyed municipalities. TAZs generally vary in geographic size based on population, as well as the surrounding road network, or geographical features. The available data for each TAZ contains a series of variables for understanding traffic patterns or behaviour. This includes such variables and data as trip generation, mode choice, trip time origination, trip purposes, trip distance, trip origin and destination, and household vehicle ownership, as well as more general factors and/or data such as age, gender, and dwelling typologies. This allows the TTS Survey to be useful in analyzing traffic patterns and behaviour at a relatively smaller scale. The TTS Survey is a five percent random selection survey which is conducted both by phone, and by internet in the most recent undertaking. The survey is conducted every five years to mirror Census surveying. The most recent survey was conducted in 2011. This is the data set that will be used within the remainder of this study. The TAZs used for analysis can be seen visually in Figure 2. Areas in white are not applicable for analysis as they either feature no residential land uses, or do not have any commuting population.

The TTS Survey is one of the largest surveys undertaken of its kind, and is unique to the GTHA. However, since the TTS Survey is a five percent random selection survey, it must use an expansion factor based on each zone's respective population to provide representable data. In using an expansion factor, accuracy is lost. This is simply because it impossible to 


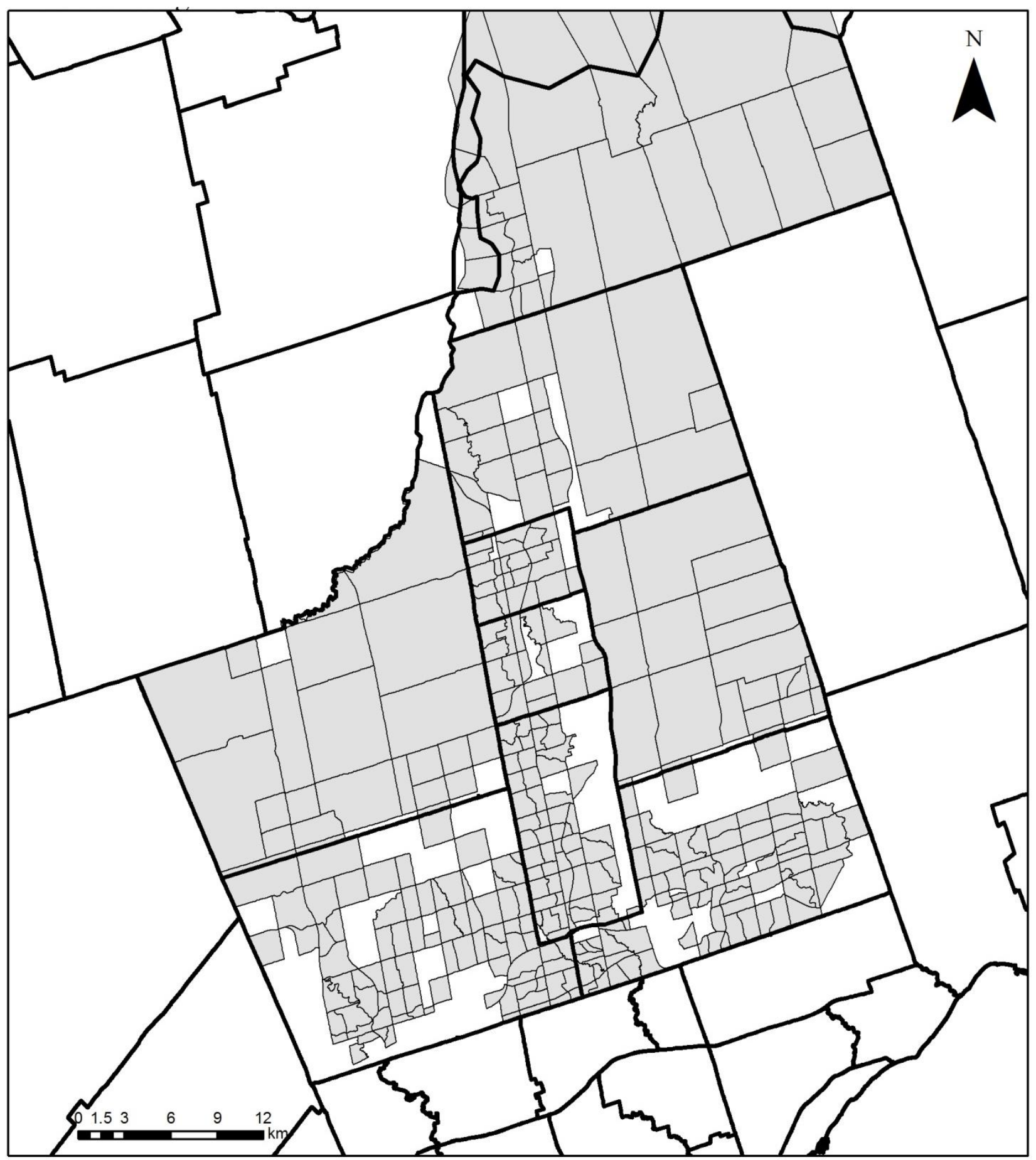

Figure 2: York Region TAZs Used for Analysis

comprehensively survey the entire population. As a result, not all data may be truly

representative of the areas which are being analyzed. There are additional limitations with TTS data. TTS data does not include household income, or immigration status, which are two 
variables that have been shown to be significant factors in determining mode choice (Lo, Shalaby, Alshalalfah, 2011; Heisz, Schellenberg, 2004). Furthermore, since 2011 data are the most current, findings will not represent current conditions most accurately. Additional intensification as well as transit improvements has occurred in York Region and throughout the GTHA since the 2011 TTS Survey has been conducted. However, the findings that will be presented will reflect travel behaviour during 2011, when York Region intensification policies were well in place and being practiced.

TTS data will be used as the input data for the regression model. Since TTS data captures trips throughout the day, the estimated model will be for that of a typical weekday AM commuting period in York Region. In an attempt to capture as many commutes as possible, the estimated model will be for the time period of 6:00AM to 11:00AM. This will capture a large portion of the morning commuting performed by workers in York Region. Furthermore, the data have been filtered for home-based work trips. All collected data have been filtered in this manner for consistency. The first trip of the day to work is typically an accurate trip to capture. This is because the trip must originate from home and is always destined for the workplace. For this reason, the AM peak period is appropriate for commuting behaviour analysis.

A set of variables will be included in the multiple regression model for control to attempt to eliminate any confounded effects that density has on transit usage in York Region. The regression performed will be a linear multiple regression. All included variables have been measured at the TAZ level. This will include primarily density as one independent variable. The dependent variable in the model will be that of transit mode split. Other independent variables for testing will include demographic variables being percent of the commuting population aged between 16 and 24, percent of the commuting population aged above 65 , and percent of the 
commuting population that is female. It is expected that as the percent of the population of younger persons increases, transit mode split will increase, while the same is true for older populations. Also expected is that as the percent of female population increases, transit use will increase (Heisz, Schellenberg, 2004). As for built form variables, these will include density, percent of households that are apartment dwellings, and location in respect to the VIVA transit corridors as well as GO stations. It is expected that as these variables increase in value, transit mode split will also increase. The final set of included variables will be transportation variables. These will include percent of households without a car, percent of the population in possession of a driver's licence, percent of the population in possession of a transit pass, percent of the population charged for parking at work, percent of the population with a workplace located within York Region, or the City of Toronto, and average commute distance. It is anticipated that as the percent of commuters who own a driver's licence and average commute distance increases, transit mode split will decrease. Furthermore, it is expected as the percent of households without a car, percent of commuters who are charged for parking at work, and percent of commuters in possession of a transit pass increase, transit mode split will increase.

Conducting a multiple linear regression analysis was not the only choice available to analyze the collected data. Since most variables are in the form of proportional data, other models were considered. However, the majority of the proportional data, as well as their means, lie between zero and one. Therefore, a linear regression will return a comparable prediction to other models. One other model considered was a logistic regression model. Using logistic regression, however, would have required categorizing the transit mode split data available into ranges. Doing so would reduce the accuracy of predicting mode split significantly. Therefore, multiple linear regression was chosen for the analysis. Important to consider is that the 
conducted regression model does not determine causation, but rather correlation. The results are, therefore, to be reviewed as such.

In order to evaluate and understand the changes in density and transit mode split over time, which is not addressed in the regression model, GIS has been used to map visually the extent of density and transit mode split changes within York Region. TTS data were collected for the survey year of 2006 in addition to the data collected from 2011. The comparative analysis will demonstrate if TAZs undergoing the greatest density increases are also undergoing the greatest transit mode split increases. Additionally, if TAZs experiencing an increase in density are experiencing significant increases in transit mode split. TAZs located along the Region's transit corridors have been evaluated for their density and transit mode split changes over the two survey periods as well. 


\section{Results}

A summary of the variables included in the model is displayed in Table 2. The variable

of transit mode split, which is measured as the percent of the population per TAZ that commutes

by public transit, is estimated as having a mean of $10.72 \%$. The mean of transit mode split is

Table 2: TAZ Variable Descriptions (2011)

\begin{tabular}{|c|c|c|c|}
\hline \multirow[b]{2}{*}{ Variable } & \multicolumn{3}{|l|}{2011} \\
\hline & Description & Mean & $\begin{array}{l}\text { Standard } \\
\text { Deviation }\end{array}$ \\
\hline Transit Mode Split & $\begin{array}{l}\text { Percent of the commuting population per TAZ } \\
\text { that commutes by public transit }\end{array}$ & 0.1072 & 0.1038 \\
\hline \multicolumn{4}{|l|}{ Demographics } \\
\hline$\%$ Aged $16-24$ & $\begin{array}{l}\text { Percent of the commuting population per TAZ } \\
\text { aged } 16-24\end{array}$ & 0.0709 & 0.0932 \\
\hline$\%$ Aged $65+$ & $\begin{array}{l}\text { Percent of the commuting population per TAZ } \\
\text { aged } 65+\end{array}$ & 0.0479 & 0.1195 \\
\hline$\%$ Female Population & $\begin{array}{l}\text { Percent of the commuting population per TAZ } \\
\text { that is female }\end{array}$ & 0.4565 & 0.1640 \\
\hline \multicolumn{4}{|l|}{ Built Form } \\
\hline Density (persons per sq. km.) & $\begin{array}{l}\text { Overall density per TAZ in persons per square } \\
\text { kilometre }\end{array}$ & 1914.0096 & 1806.5077 \\
\hline$\%$ Residing in Apartment Dwellings & $\begin{array}{l}\text { Percent of the commuting population per TAZ } \\
\text { residing in apartment dwellings }\end{array}$ & 0.0684 & 0.1929 \\
\hline $\begin{array}{l}\text { TAZ Located on a Transit Corridor } \\
\text { (within } 500 \mathrm{~m} \text { ) }\end{array}$ & $\begin{array}{l}\text { TAZ is located within a } 500 \mathrm{~m} \text { buffer zone of } \\
\text { VIVA Transit corridors (yes/no) }\end{array}$ & 0.3548 & 0.4792 \\
\hline $\begin{array}{l}\text { TAZ Located nearby a GO Station } \\
(1000 \mathrm{~m})\end{array}$ & $\begin{array}{l}\text { TAZ is located within a } 1000 \mathrm{~m} \text { buffer zone of a } \\
\text { GO Station (yes/no) }\end{array}$ & 0.1730 & 0.3788 \\
\hline $\begin{array}{l}\% \text { of Commuters Workplace in York } \\
\text { Region }\end{array}$ & $\begin{array}{l}\text { Percent of the commuting population per TAZ } \\
\text { with a workplace in York Region }\end{array}$ & 0.5134 & 0.2235 \\
\hline$\%$ of Commuters Workplace in Toronto & $\begin{array}{l}\text { Percent of the commuting population per TAZ } \\
\text { with a workplace in Toronto }\end{array}$ & 0.3269 & 0.2134 \\
\hline \multicolumn{4}{|l|}{ Transportation } \\
\hline$\%$ Households with no Cars & $\begin{array}{l}\text { Percent of the commuting population per TAZ } \\
\text { residing in a household with no cars }\end{array}$ & 0.0061 & 0.0275 \\
\hline$\%$ Possess a Driver's Licence & $\begin{array}{l}\text { Percent of the commuting population per TAZ } \\
\text { that possesses a driver's licence }\end{array}$ & 0.9749 & 0.0518 \\
\hline$\%$ Possess a Transit Pass & $\begin{array}{l}\text { Percent of the commuting population per TAZ } \\
\text { that possesses a transit pass }\end{array}$ & 0.0997 & 0.1136 \\
\hline $\begin{array}{l}\% \text { Charged for Parking at Place of } \\
\text { Work }\end{array}$ & $\begin{array}{l}\text { Percent of the commuting population per TAZ } \\
\text { that is charged for parking at work }\end{array}$ & 0.1659 & 0.1382 \\
\hline $\begin{array}{l}\text { \% Commute Distance Above YR } \\
\text { Average }\end{array}$ & $\begin{array}{l}\text { Percent of the commuting population per TAZ } \\
\text { with commutes above the York Region average }\end{array}$ & 0.3892 & 0.2207 \\
\hline
\end{tabular}


slightly greater than its standard deviation. This suggests a high level of variability in transit mode split. This is to be expected for a diverse geographic area such as York Region. As for the variable of density, the mean density was estimated at approximately 1,914 persons per square kilometre. This is also slightly greater than its standard deviation indicating a high level of variability which is also to be expected for York Region.

The results of the multiple linear regression model can be seen in Table 3. Reported are the outputs of the model for transit mode split in 2011 based on the independent variables exhibited by the TAZs. The overall performance of the model is good to great with an $\mathrm{R}^{2}$ of

Table 3: TAZ Regression Results (2011)

\begin{tabular}{|c|c|c|c|c|}
\hline \multirow[b]{2}{*}{ Variable } & \multicolumn{4}{|c|}{2011} \\
\hline & Coefficients - $\beta$ & Std. Error & $\mathrm{t}$ & $\rho$ \\
\hline (Constant) & -1.598322 & 6.652735 & & \\
\hline \multicolumn{5}{|l|}{ Demographics } \\
\hline$\%$ Aged $16-24$ & 0.038487 & 0.035016 & 1.099123 & 0.272530 \\
\hline$\%$ Aged $65+$ & 0.011845 & 0.026808 & 0.441834 & 0.658904 \\
\hline$\%$ Female Population & 0.058042 & 0.019988 & 2.903870 & 0.003939 \\
\hline \multicolumn{5}{|l|}{ Built Form } \\
\hline Density (persons per sq. km.) & 0.000700 & 0.000201 & 3.486812 & 0.000556 \\
\hline$\%$ Residing in Apartment Dwellings & 0.010329 & 0.017365 & 0.594825 & 0.552376 \\
\hline TAZ Located on a Transit Corridor (within 500m) & -0.494181 & 0.696584 & -0.709435 & 0.478565 \\
\hline TAZ Located nearby a GO Station (1000m) & 0.002187 & 0.828583 & 0.002639 & 0.997896 \\
\hline$\%$ of Commuters Workplace in York Region & -0.002775 & 0.021461 & -0.129295 & 0.897204 \\
\hline$\%$ of Commuters Workplace in Toronto & 0.092427 & 0.027688 & 3.338139 & 0.000942 \\
\hline \multicolumn{5}{|l|}{ Transportation } \\
\hline$\%$ Households with no Cars & 0.229092 & 0.117173 & 1.955155 & 0.051424 \\
\hline$\%$ Possess a Driver's Licence & -0.041804 & 0.066175 & -0.631727 & 0.528011 \\
\hline$\%$ Possess a Transit Pass & 0.373389 & 0.030829 & 12.111740 & 0.000000 \\
\hline \% Charged for Parking at Place of Work & 0.262430 & $\mathbf{0 . 0 3 3 6 4 7}$ & 7.799456 & 0.000000 \\
\hline \multirow[t]{3}{*}{$\%$ Commute Distance Above YR Average } & 0.028673 & 0.015627 & 1.834871 & 0.067442 \\
\hline & & & $\mathrm{R}^{2}=$ & 0.707 \\
\hline & & & $\mathrm{N}=$ & 338 \\
\hline
\end{tabular}


0.707. This means that based on this model and the TTS data available, approximately $71 \%$ of the factors that explain transit mode split in York Region for home-based work trips during the morning commuting period (6:00AM - 11:00AM) are explained and represented. The large number of TAZs within York Region $(\mathrm{N}=338)$ also allowed for the inclusion and testing of a considerable number of variables for control in addition to density. Few variables were excluded from the model. These include the percent of commuters aged 25 to 64, percent of households that own a car, and percent of persons with commute distances below the York Region average of approximately 18 kilometres.

Of the three included demographic variables for control, only the percent of female commuters in a TAZ was found to be significant at the $95 \%$ confidence level. Both the percent of commuters aged 16 to 24 and the percent of commuters aged 65 or older were found to have pvalues that are not statistically significant. This indicates that increasing or decreasing the amount of younger or older commuters does not have a statistically significant impact on transit mode split in York Region. As for the percent of the commuting population that is female, a positive correlation with transit mode split was returned. A $10 \%$ increase in the percent of the female commuting population is found to result in a $0.58 \%$ in transit mode split in York Region.

A larger number of variables related to built form and physical location were included in the model for control. The variable of the percent of the commuting population living in apartment dwellings was found to not be statistically significant. This is somewhat a surprising result as there is no correlation between apartment residents and transit usage. Similarly, the percent of the commuting population working within York Region was also found to be statistically insignificant. This is not considered to be a surprising outcome. However, the percent of the commuting population that has a workplace located in the City of Toronto is 
returned as being significant at the $95 \%$ confidence level. The correlation between the percent of those working in the City of Toronto in a TAZ and transit mode split is positive. A $10 \%$ increase in the population working in the City of Toronto results in a $0.92 \%$ increase in transit mode split in York Region. What is found to be the most surprising result of the built form variables is that residing in a TAZ located along one of the major transit corridors in York Region is largely insignificant. The interpretation of this result is that whether or not a commuter is located within 500 metres of a transit corridor or not has no significant impact on their choice to use transit. The same is true for those located within one kilometre of a GO Station.

As for the primary variable of interest in this model being density, it was found to be statistically significant at the $95 \%$ confidence level. The hypothesis, being density is a statistically significant variable in explaining transit mode split is, therefore, accepted based on these findings. Density returned a very low coefficient for predictability. However, this is due to the scale at which density is represented within this model being in persons per square kilometre. A one person increase per square kilometre in York Region is found to result in a $0.0007 \%$ increase in transit mode split. In other words, increasing density by 1000 people per square kilometre will result in a transit mode split increase of $0.70 \%$. The correlation between density and transit mode split as anticipated is positive, and suggests that denser zones in York Region will exhibit higher transit usage.

The final set of variables included in the model as control variables were those related to factors of transportation. While generally unexpected, the percent of the commuting population that possesses a driver's licence was not found to be statistically significant at the $95 \%$ confidence level. In the context of York Region, however, this is not a surprising result. This is likely due to the high level of auto usage as well as the very large number of commuters in York 
Region that do possess a driver's licence. Therefore, this finding suggests that those choosing to commute in York Region by transit are doing so despite their legal ability to drive. Also found to be insignificant in the model was the percent of the commuting population with commutes in excess of the York Region average. Using TTS data, the average commuting distance of those travelling to work from home during the observed period (6:00AM - 11:00AM) in 2011 was estimated to be 18 kilometres.

Two of the included variables related to transportation are found to have statistical significance. Firstly, the percent of the commuting population that possesses a transit pass is found to have a positive correlation with transit mode split. This is an anticipated result. For every $1 \%$ increase in the population that possesses a transit pass, transit mode split is estimated to increase by $0.37 \%$ in York Region. Also an anticipated result is the significance of the percent of commuters being charged for parking at their workplace. The positive correlation between the percent of commuters being charged for parking and transit mode split is found to be for every $1 \%$ increase in commuters charged for parking at work, transit mode split increases by $0.26 \%$. The final variable to be discussed is the percent of households that do not own a car. While this variable is found to not be statistically significant at just over the $95 \%$ confidence level ( $\mathrm{p}=$ 0.051), it is still worth noting. The correlation between percent of no car households and transit mode split is expectedly positive. Estimated is that for every $1 \%$ increase in the percent of households with no car, transit mode split increases by $0.23 \%$. Most transportation variables are, therefore, found to have an impact on transit mode split. 


\section{Discussion}

A statistically significant correlation between density and transit modal split has been returned in the regression model. It can, therefore, be expected that denser neighbourhoods or areas in York Region, will have greater proportions of their population using public transit to commute to work during the weekday morning. Based on the results, it is also estimated that as neighbourhoods continue to experience an increase in density, or continue to intensify in York Region, the percent of the population using public transit to commute to work during the weekday morning will increase as well. The positive correlation between transit and density, however, is to be expected. This is due to public transit becoming a more viable form of transportation as density increases. Increased density typically means the greater concentration of activity, residents, and, therefore, destinations and origins. It becomes easier to target the trip purposes of more individuals if activities and work destinations are located within the same, or nearby areas. To further illustrate the correlation between density and transit mode split in York Region, GIS was used to map both the TAZs with the highest densities, and the highest transit mode split. The 2011 density and transit mode split of York Region can be seen in Figure 3, and Figure 4, respectively.

What is also apparent is that a large amount of TAZs containing the greatest densities, and transit mode split, are located on, or around the major transit corridors. As found in the regression model, however, the location of a TAZ on or nearby a major transit corridor is not a statistically significant predictor in estimating an increase in transit mode split. The statistically significant relationship between density and transit usage may, therefore, be the primary means in explaining the overlap of denser zones with greater transit usage. 
2011 York Region Density

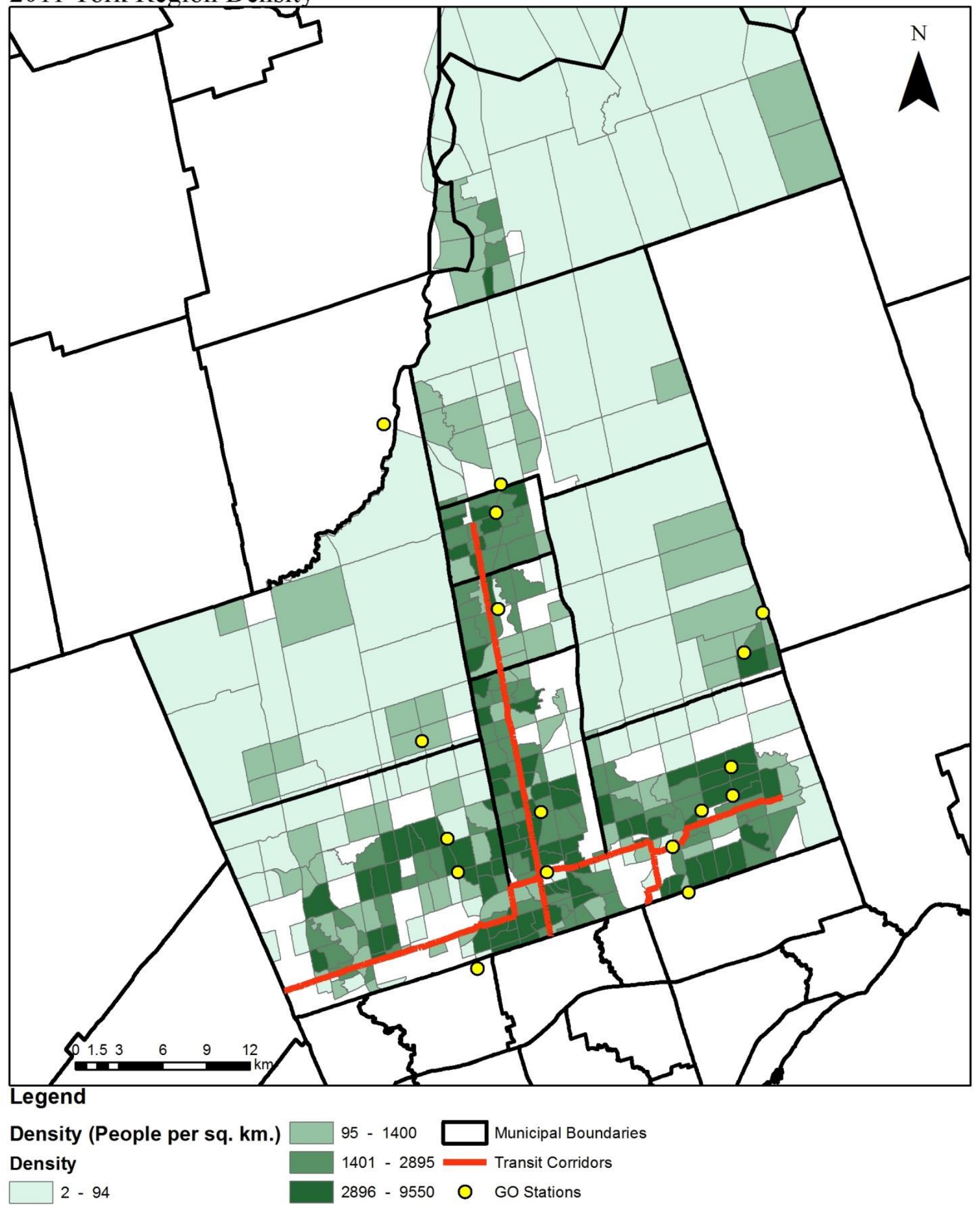

Figure 3: 2011 York Region Density (People per sq. km.) 
2011 York Region Transit Mode Split

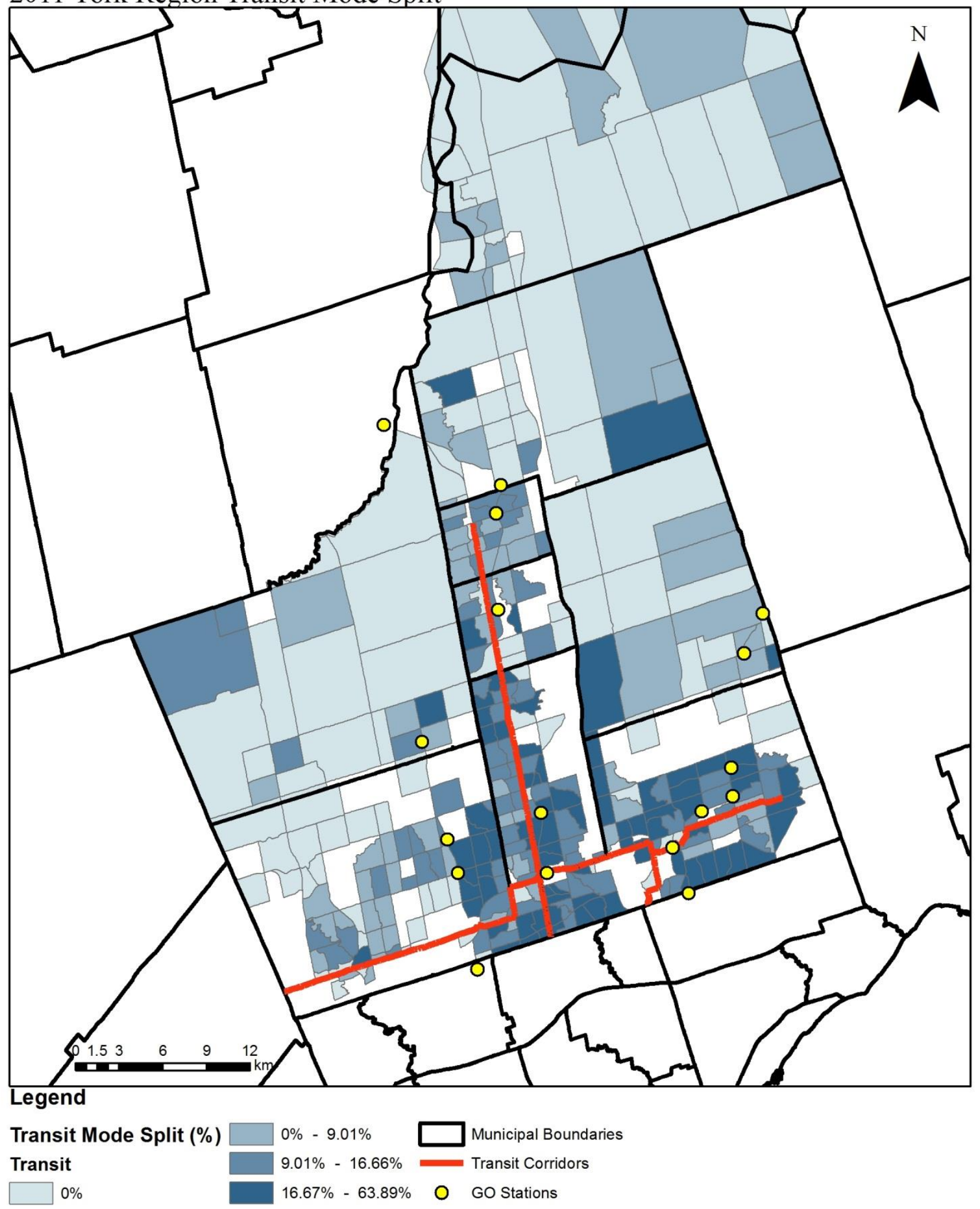

Figure 4: 2011 York Region Transit Mode Split (\%) 
It appears as planning for increases in density in York Region is a strategic policy to reduce auto dependency, increase transit ridership, and achieve external goals related to excessive auto usage such as improving air quality, reducing noise pollution, and increasing road safety. York Region has, and continues to plan for intensification along its "Corridors", and within its "Centres". This "Centres" and "Corridors" intensification strategy looks to have contributed to the Region's "Centres" and "Corridors" containing some of the highest population densities, and relatively high transit mode split. Furthermore, a resultant increase in transit usage in outer suburban areas like York Region is a primary planning strategy of the practiced intensification policies. However, results while statistically significant and somewhat encouraging are not overwhelming.

Results indicate that increasing the population density of a given TAZ in York Region by 1000 persons per square kilometre would result in a transit mode split increase during the weekday morning commute period by $0.70 \%$. This is a marginal increase in transit mode split. Given that the densest TAZ in York Region in 2011 was 9550 persons per square kilometre, doubling this zone's density to 19,100 persons per square kilometre would increase transit mode split for the weekday morning commute by approximately $6.7 \%$. This is a very large increase in density needed to achieve a large transit ridership increase. Alternatively, to understand what the impact an increase in density would have on private auto mode split in York Region during the weekday morning commute period, a sample scenario can be created using available averages. The average TAZ in York Region has a density of approximately 1,914 persons per square kilometre, along with an average transit mode split of $10.72 \%$. The York Region average scenario is summarized in Table 4. If the average York Region TAZ were to double in density, 
resulting in a new density of 3,828 persons per square kilometre, as per findings from the regression model, transit mode split would increase by $0.70 \%$ per 1000 persons added per

Table 4: York Region Average Density and Mode Split Change Scenario (2011)

\begin{tabular}{|c|c|c|c|c|c|c|}
\hline \multirow[b]{2}{*}{ Mode } & \multicolumn{2}{|c|}{ York Region Average } & \multicolumn{4}{|c|}{ Double York Region Average Density } \\
\hline & $\begin{array}{l}\text { Mode } \\
\text { Split }\end{array}$ & $\begin{array}{c}\text { \# of } \\
\text { Commuters }\end{array}$ & $\begin{array}{l}\text { Mode } \\
\text { Split }\end{array}$ & $\begin{array}{l}\text { Mode Split } \\
\text { Change }\end{array}$ & $\begin{array}{c}\# \text { of } \\
\text { Commuters }\end{array}$ & $\begin{array}{c}\text { \# of } \\
\text { Commuter } \\
\text { Change }\end{array}$ \\
\hline Private Auto & $81.85 \%$ & 1,566 & $80.51 \%$ & $-1.34 \%$ & 3,082 & $+1,516$ \\
\hline Public Transit & $10.72 \%$ & 205 & $12.06 \%$ & $+1.34 \%$ & 462 & +257 \\
\hline Auto Passenger & $6.04 \%$ & 116 & $6.04 \%$ & $0 \%$ & 231 & +115 \\
\hline Active Transportation & $1.15 \%$ & 22 & $1.15 \%$ & $0 \%$ & 44 & +22 \\
\hline \multirow[t]{2}{*}{ Other } & $0.25 \%$ & 5 & $0.25 \%$ & $0 \%$ & 9 & +4 \\
\hline & $100 \%$ & 1,914 & $100 \%$ & - & 3,828 & +1914 \\
\hline
\end{tabular}

square kilometre. This would return a transit mode split increase for the average TAZ of $1.34 \%$. Assuming the increase in transit mode split is consumed solely from private auto, the average auto mode split would decrease to $80.51 \%$ from $81.85 \%$. Overall, since the increase in transit mode split is still minimal, of the 1,914 new persons added to the average York Region TAZ in this scenario, estimated is that 1,516 would commute by private auto during the weekday morning period. This is a large increase in auto traffic in the average York Region TAZ at the expense of doubling its density. Of course, the provided scenario is based on a number of assumptions and is likely not an accurate estimation. However, it is meant to demonstrate the large auto traffic increase that can result alongside density increases when minimal or small changes are made to transit mode split.

Density and transit mode split, therefore, are statistically correlated, but the impact of density on mode split is not drastic. A more in-depth analysis of the TAZ data comparing the density and transit mode split relationship between 2006 and 2011 is also worth discussing in relation to regression model findings. Table 5 displays a comparison of the transit mode split 
characteristics of TAZs in York Region. Overall, the number of TAZs in York Region using transit increased. More interestingly however, the number of TAZs which have the greatest

Table 5: York Region Density-Transit Relationship Comparison (2006 - 2011)

\begin{tabular}{|c|c|c|c|}
\hline \multirow[b]{2}{*}{ All Zones } & \multicolumn{3}{|c|}{ Comparison } \\
\hline & 2006 & 2011 & $\begin{array}{c}\text { Change from } \\
2006-2011\end{array}$ \\
\hline Using Transit & $67 \%$ & $72 \%$ & $5 \%$ \\
\hline Not Using Transit & $33 \%$ & $28 \%$ & $-5 \%$ \\
\hline \multicolumn{4}{|l|}{ Densest TAZs (75th Percentile) } \\
\hline Have Highest Transit Mode Split (75th Percentile) & $46 \%$ & $42 \%$ & $-4 \%$ \\
\hline Not Using Transit & $0 \%$ & $0 \%$ & $0 \%$ \\
\hline \multicolumn{4}{|l|}{ Highest Transit Mode Split TAZs (75th Percentile) } \\
\hline Have Highest Density (75th Percentile) & $48 \%$ & $46 \%$ & $-2 \%$ \\
\hline \multicolumn{4}{|l|}{ Average Transit Mode Split } \\
\hline Densest TAZs (75th Percentile) & $15 \%$ & $16 \%$ & $1 \%$ \\
\hline TAZs Located on a Transit Corridor (within 500m) & $13 \%$ & $15 \%$ & $2 \%$ \\
\hline TAZs Located near a GO Station (within 1000m) & $12 \%$ & $13 \%$ & $1 \%$ \\
\hline \multicolumn{4}{|l|}{ TAZs Located on a Transit Corridor (within 500m) } \\
\hline Using Transit & $85 \%$ & $84 \%$ & $-1 \%$ \\
\hline Not Using Transit & $15 \%$ & $16 \%$ & $1 \%$ \\
\hline Have Highest Transit Mode Split (75th Percentile) & $40 \%$ & $28 \%$ & $-12 \%$ \\
\hline Have Highest Density (75th Percentile) & $34 \%$ & $33 \%$ & $-1 \%$ \\
\hline \multicolumn{4}{|l|}{ TAZs Located near a GO Station (within $1000 \mathrm{~m}$ ) } \\
\hline Using Transit & $83 \%$ & $85 \%$ & $2 \%$ \\
\hline Not Using Transit & $17 \%$ & $15 \%$ & $-2 \%$ \\
\hline Have Highest Transit Mode Split (75th Percentile) & $32 \%$ & $29 \%$ & $-3 \%$ \\
\hline Have Highest Density (75th Percentile) & $31 \%$ & $36 \%$ & $4 \%$ \\
\hline
\end{tabular}

densities, and also have the greatest transit mode split, decreased slightly from 2006 to 2011. Comparatively, the number of TAZs which have the greatest transit mode split alongside the 
greatest densities also decreased slightly. The most surprising change from to 2006 to 2011 is the considerable decrease in TAZs located on a transit corridor that contain the greatest transit mode split, as well as a very slight decrease in overall transit usage. It would be expected over this five year period that TAZs located along transit corridors would experience an increase in transit mode split. This is not the case. This finding also supports the findings from the multiple linear regression returning no statistically significant correlation between transit mode split, and a TAZ's location on a transit corridor. A final unexpected occurrence is the lack of change in the average transit mode split in the densest TAZs in York Region, as well as TAZs located on a transit corridor.

Table 6 provides further insight into transit mode split changes that have occurred alongside density increases in York Region TAZs from 2006 to 2011. Of all TAZs in York

Table 6: York Region Density Increase-Transit Change Relationship (2006 - 2011)

\begin{tabular}{|c|c|c|c|}
\hline \multirow[b]{2}{*}{ All TAZs with Changing Density } & \multicolumn{3}{|c|}{$\%$ of TAZs } \\
\hline & $\begin{array}{c}\% \text { TAZs with } \\
\text { Increasing Transit }\end{array}$ & $\begin{array}{l}\text { \% TAZs with no } \\
\text { Transit Change }\end{array}$ & $\begin{array}{c}\% \text { TAZs with } \\
\text { Decreasing Transit }\end{array}$ \\
\hline TAZs with Increasing Density & $46 \%$ & $27 \%$ & $27 \%$ \\
\hline TAZs with Decreasing Density & $29 \%$ & $36 \%$ & $35 \%$ \\
\hline $\begin{array}{l}\text { TAZs with Highest Density Increase } \\
\text { (75th Percentile) }\end{array}$ & $\begin{array}{c}\text { \% TAZs with Highest } \\
\text { Transit Change (75th } \\
\text { Percentile) }\end{array}$ & $\begin{array}{c}\% \text { TAZs with } \\
\text { Increasing Transit }\end{array}$ & $\begin{array}{c}\% \text { TAZs with } \\
\text { Decreasing Transit }\end{array}$ \\
\hline $\begin{array}{l}\text { TAZs with Highest Density Change } \\
\text { ( } 75 \text { th Percentile) }\end{array}$ & $28 \%$ & $72 \%$ & $28 \%$ \\
\hline $\begin{array}{l}\text { TAZs Located on a Transit Corridor } \\
\text { or Near a GO Station }\end{array}$ & $\begin{array}{c}\text { \% TAZs with Highest } \\
\text { Transit Change (75th } \\
\text { Percentile) }\end{array}$ & $\begin{array}{c}\% \text { TAZs with } \\
\text { Increasing Transit }\end{array}$ & $\begin{array}{c}\% \text { TAZs with } \\
\text { Decreasing Transit }\end{array}$ \\
\hline TAZs Located on a Transit Corridor & $10 \%$ & $42 \%$ & $40 \%$ \\
\hline TAZs Located Near a GO Station & $10 \%$ & $49 \%$ & $31 \%$ \\
\hline
\end{tabular}


Region experiencing an increase in density from 2006 to 2011, a considerable number of these TAZs experienced a reduction in transit mode split. Furthermore, almost one-third of TAZs experiencing a decrease in density also experienced an increase in transit usage. Of the TAZs experiencing the greatest increases in density over the five year time period, $28 \%$ of those TAZs were TAZs that also experienced the greatest increases in transit mode split. This is a result that would be expected of areas undergoing the strongest density changes. Worth noting, however, is that $28 \%$ of the TAZs experiencing the greatest density increases actually witnessed a decrease in transit mode split. This is somewhat surprising. Finally, only a small proportion of TAZs located on a transit corridor experienced the greatest increases in transit mode split from 2006 to 2011. Many TAZs along transit corridors were found to experience a decreasing transit mode split. This finding is also somewhat surprising.

While results from the regression model indicate a statistically significant correlation between increasing density and transit, a comparison of TAZs from 2006 to 2011 provides insight into what appears to be a lack of correlation between high increases in density, location on a transit corridor, and transit mode split. Figure 5 and Figure 6 display the changes in York Region density and transit mode split from to 2006 to 2011, respectively.

Overall, density does appear to be a factor in resulting in greater uses of transit. However, there are many other factors that are also playing an important role in influencing travel behaviour in York Region. Since the density of outer suburban areas such as York Region is relatively low in comparison to municipalities such as the City of Toronto, transit is generally not an advantageous mode of transportation over auto for many commuters. Increasing density is the obvious response to this issue, unfortunately increasing density only responds to a fraction of the variables influencing travel behaviour in outer suburban areas. Since intensification in outer 
2006 - 2011 York Region Density Change

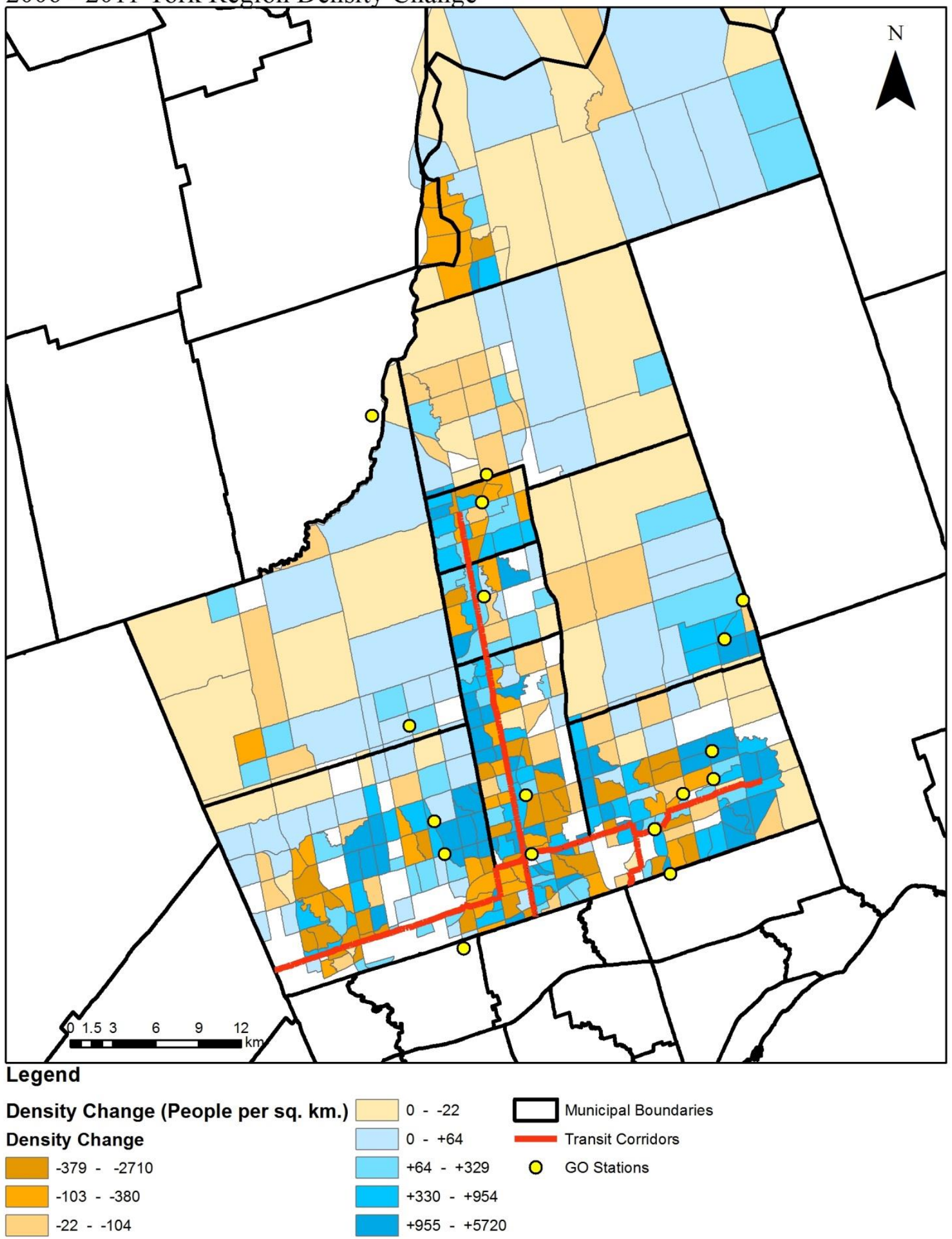

Figure 5: 2006 - 2011 York Region Change in Density (People per sq. km.) 
2006 - 2011 York Region Transit Mode Split Change

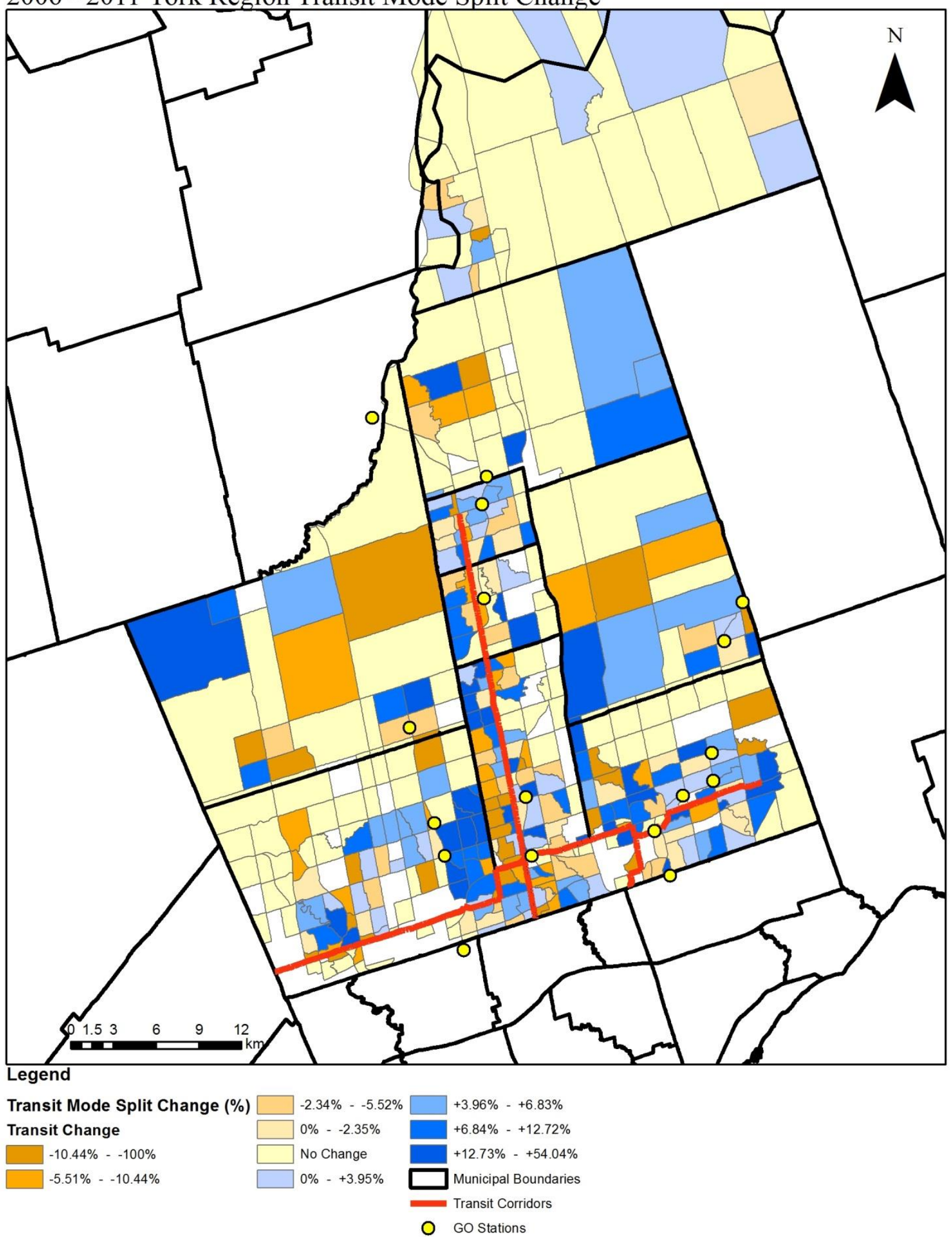

Figure 6: 2006 - 2011 York Region Transit Mode Split Change (\%) 
suburban regions such as York Region is often applied to areas where built form is already present and travel behaviours are well in place, changing that behaviour is not a simple process. Much of the travel behaviour that exists is dependence on the car to be mobile. This is largely a consequence of the type of built form that is found to precede intensification practices.

Charged parking at one`s workplace, possession of a transit pass, and not owning a car were all variables found to be significant in the regression model. More importantly, these variables were estimated to have a strong impact on transit mode split. For every $1 \%$ increase in the percent of commuters who are charged for parking at work, and possess a transit pass, transit mode split is estimated to increase by $0.63 \%$. This is likely the case because charging for parking at work is a direct disincentive to drive, while possessing a transit pass is a direct incentive to take transit. Charging for parking presents to a driver, a visible monetary cost for their choice to drive in addition to paying for fuel. It appears in the context of York Region, that charging employees for parking at work is an effective means of altering travel behaviour. Furthermore, numerous variables that could not be tested are also likely to have a significant impact on transit mode split, such as parking spaces available at home, and total commute time.

Overall, findings from the linear regression model and comparison of TTS data from 2006 to 2011, largely align with the existing literature (Cervero, King, 2010; Melia, Parkhurst, and Barton, 2010; Jun, 2008; Susilo, Maat, 2007; Schwanen, Dijst, Dieleman, 2004). That is, density is a statistically significant variable in positively influencing transit usage, but its effect is minimal compared to other transportation variables. These findings, however, should not be generalized as they are specific to the geography of York Region. While it cannot be concluded that increasing density in York Region will lead to reduced air quality, worsened traffic congestion, and decreased road safety as argued by Melia, Parkhurst, and Barton (2010), 
Echenique, Homewood (2003) and Richardson (2000), findings do suggest that a drastic increase in density will not defer auto trips sufficiently to offset the large increase in auto trips created alongside an increase in population. The suggested consequences of suburban intensification may then result. In order to have a large increase in transit mode split in York Region, travel behaviours need to be altered primarily by means other than increasing density to avoid any unintended consequences of intensification. 


\section{Conclusion}

Findings from multiple linear regression of TTS data in York Region reveal that while density and transit mode split are significantly correlated for morning weekday home-based work trips, increasing density does not have a drastic impact on increasing transit mode split. This is consistent with much of the reviewed literature. Comparative analysis between 2006 and 2011 TTS data further reveals that large increases in density, as well as density increases generally in York Region, are not occurring alongside transit mode split increases. Many TAZs between 2006 and 2011 were found to experience decreasing transit mode split concurrent with increasing density, while the overall average transit mode split of the densest TAZs, as well as TAZs located directly on major transit corridors, did not change considerably over the five year period. Even so, transit mode split in York Region did increase from 2006 to 2011. This indicates that other factors are more influential in increasing transit mode split, such as charging for parking at work, or possessing a transit pass, as found in the regression model.

With the Growth Plan requiring $40 \%$ of all new development in Ontario to be by means of intensification by 2015, municipalities in the Province need to continue planning for higher density growth. In York Region, intensification planning has been ongoing. Numerous areas of the Region have undergone, and will continue to undergo immense change in terms of built form. The creation of numerous high density nodes in the Region means the introduction of a large number of new jobs, and residents. How residents travel to and from their household and workplace, however, is hoped to be by means of public transit. Indeed, intensification is advocated as positively impacting transit usage. Unfortunately, if these high density nodes are planned to be primarily supportive of the car, it is likely the travel behaviour exhibited within these nodes will largely reflect the travel behaviour of the rest of the outer suburban area. Travel 
behaviour which is largely reliant upon the car. Furthermore, without deferring trips sufficiently away from private auto, any increase in transit ridership in intensified areas is likely to be overshadowed by a large increase in car trips as a result of the newly introduced population. The result will be an even greater number of cars on the road, leading to issues of increasing congestion, decreasing air quality, and decreasing road safety, impacting active modes of transportation. Outer suburban regions like York Region are often considered to be car-oriented, experiencing an array of traffic issues. The primary mode of transportation that combats car usage is public transit. To make public transit viable in areas like the outer suburbs, density increases are often considered necessary. However, changing travel behaviours is difficult, and is the root of the car dependency issue. A drastic increase in density without more assertively targeting well developed travel behaviours in outer suburban areas, therefore, has the potential to result in a large increase in car traffic. 


\section{Recommendations}

The findings from this study are not to reduce the important of density in creating or assisting transportation systems to be supportive of alternate modes of transportation such as transit. Rather, findings are to increase the importance of other influential transportation policies in altering outer suburban travel behaviour. What the findings have indicated is that density is one small portion of the changes that need to occur in the outer suburban region of York Region, and, therefore, increasing density along transit corridors alone will not have a large impact in altering existing travel behaviour. Existing travel behaviour that is, largely, auto dependent. As discussed previously, in the case of York Region, auto dependent travel behaviours are well in place due to the transportation realities associated with the dominant built form of the Region. This is low-density, single-detached neighbourhoods, connected by a grid pattern of major arterial roads. Intensification, and creating higher densities, is a crucial aspect of making public transit itself viable, but it will likely not create the changes in travel behaviour needed to take advantage of the increased viability of the transit systems. This understanding while based on the findings presented here, is also informed by the existing literature (Cervero, King, 2010; Melia, Parkhurst, and Barton, 2010; Jun, 2008; Susilo, Maat, 2007; Schwanen, Dijst, Dieleman, 2004). Based on this understanding of the density, transit, and outer suburban context relationship, a series of recommendations are devised for York Region policies, as well as other similar outer suburban areas that wish to address issues of auto dependency.

Two factors that reinforce auto dependent travel behaviours of outer suburban commuters are unlimited parking at home, as well as free and unlimited parking at the destination (Rye, and Ison, 2005; Millard-Ball, 2002; Shoup, 1995). Removing or altering these two factors will create strong disincentives toward driving. A commuter who is deciding which mode of transportation 
to choose will be less likely to favour auto if they are aware that parking may not be available at their destination, or that the parking available at the destination will be charged. Findings from the multiple regression suggest that charging for parking at work leads to an increase in transit mode split. Incidentally, a recommended strategy for York Region is to explore methods of increasing the number of office locations, or large employment facilities that charge employees for parking.

Furthermore, an important recommendation for York Region involves lowering minimum parking requirements amongst its lower-tier municipalities. Minimum parking standards in lower density suburban areas have long been considered excessive (Millard-Ball, 2002; Shoup, 1995). Furthermore, that the presence of excessive, free, and essentially unlimited parking acts as a major incentive to use private auto exclusively. Restricting the supply of parking is an effective means to altering travel behaviour (Millard-Ball, 2002). This is because a parking spot at the trip destination will not be guaranteed, in addition to the possibility of having limited spaces at home to store a household's vehicle/s. Similarly to charging for parking at a workplace, there is a need for the existence of disincentives acting against the use of private auto to compliment the incentives encouraging public transit usage, such as efficient transit systems, and the clustering of activities in high density nodes. York Region should strongly encourage its lower-tier municipalities to set a maximum parking standard, in addition to creating intensification areaspecific parking standards that prioritize public transit.

York Region is already largely built upon with excessive minimum parking standards. However, it is the areas that will be potentially intensified where minimum parking standards can still be altered due to the new forms of development awaiting construction. It is, therefore, crucial that appropriate parking standards, such as setting a maximum standard, conducive to 
prioritizing public transit usage, be set before extensive intensification occurs. Consulting The Corporation of the City of Vaughan By-Law 1-88, City of Markham Parking Standards By-Law 28-97, and The Corporation of the Town of Newmarket Zoning By-Law 2010-40, reveals that no maximum parking standards are set, and the minimum parking standards appear to be excessive for intensified areas. Furthermore, that no area-specific parking standards which directly target the primary nodes or corridors of intensification exist. This means parking standards for higher density built forms, such as apartment dwellings, are blanketed across each of the municipalities. For Markham, apartment dwellings are to be constructed with parking at a minimum rate of 1.25 spaces per unit, while in Vaughan the minimum rate is 1.50 spaces per unit. Finally, Newmarket also requires a minimum of 1.50 spaces per apartment dwelling unit. Therefore, the minimum parking to be provided in all three circumstances is greater than the number of units to be provided. This means every unit in an apartment dwelling in an intensified area in Markham, Vaughan, or Newmarket will have at least one guaranteed parking space for a vehicle. While this is appropriate for transportation realities in an outer suburban area, it is not for an area that is intended to become a higher density node of activity with high usage of public transit. Numerous other land-uses in both municipalities also feature excessive minimum parking standards for higher density areas. For offices in Vaughan, a minimum of 3.50 spaces per 100 square metres are to be provided, in Markham, a minimum of 1.00 spaces per 30 square metres are to be provided, and in Newmarket, a minimum of 1.00 spaces per 27 square metres are to be provided. These standards are not appropriate for higher density, transit supportive areas.

Without restricting the supply of parking in intensified areas, it is unlikely travel behaviour in York Region will change as hoped for. The majority of the population will continue to travel by auto due to, primarily, its convenience. Convenience which is largely facilitated by 
guaranteed free parking. Despite the presence of higher density development, if infrastructure is largely supportive of private auto, the intensive use of the car will still result. It is difficult, if not impossible, to prioritize both means of transportation and expect comparable mode splits. Before transit can become a competitive form of transportation with private auto in outer suburban areas, travel behaviour firstly needs to be altered significantly. Increasing density and improving transit service will not alter this behaviour sufficiently, and, therefore, without creating disincentives on auto travel, increases in auto traffic and related externalities will likely result.

The reason low-density suburban public transportation is often not considered viable, is because it is difficult, if not impossible, to provide quality transit service to every resident or workplace when those residents and workplaces are sprawled across a large geographic area. Concentrating trip destinations and origins in high density nodes is, therefore, an effective means of allowing transit service to be more timely and efficient. Suburban transit can work well if these high density nodes exist and are well connected (Frisken, Wallace, 2002). The existence of higher densities in outer suburban areas is seemingly a necessary building block to reducing auto dependency. Even so, findings from this study suggest that large increases in density in the context of York Region may lead to a large rise in auto traffic. Therefore, while increasing density is important in increasing the viability of public transit, it is recommended that York Region proceed carefully, considering the potential impacts on auto traffic that may result from intensification policies. York Region along with its lower-tier municipalities, have put in policy numerous strategies to encourage the higher density development of strategic nodes. These are the centres of Markham Centre, Vaughan Metropolitan Centre, Richmond Hill Centre, and Newmarket Centre. Additionally, policies are in place to encourage higher density development along the major transit corridors being Highway 7, and Yonge Street. Markham has already 
witnessed significant changes in its built form relatively recently, with condominium dwellings and mid-rise office buildings constructed along the Highway 7 corridor. Vaughan Metropolitan Centre has also witnessed considerable change with the current construction of two high-rise condominium towers, and one office tower. These density increases may not, however, have the effect desired. York Region should give priority to focusing on altering travel behaviours prior to relatively sudden and large increases in density.

Aside from the previous recommendations, improvements to transit systems themselves are mandatory to allow public transit to be an attractive form of transportation in an auto dependent system. Giving transit systems their own right-of-way would allow for that transit system to operate unimpeded by the majority of auto traffic. This would greatly decrease travel times. Cervero, King (2010) for example found that for bus transit systems, increasing the quality of service was an effective means of deferring private auto trips in denser areas. Creating BRT (bus-rapid-transit) routes was the primary method of increasing the quality of service. Numerous transportation improvements are currently under construction in York Region that will affect both YRT and TTC systems. These are improvements that have not been captured by this study. Primarily, the TTC Yonge-University-Spadina subway extension to Vaughan Metropolitan Centre will allow for the future high density node to be connected to the TTC by higher-order transit. As for YRT systems, multiple BRT routes are planned and are currently under construction across York Region. This includes Highway 7 connecting Markham to Vaughan, and Yonge Street connecting Richmond Hill to Newmarket. The completion of these transit improvements will likely have a significant impact on transit mode split.

Overall, to conclude, recommended for York Region as well as other outer suburban municipalities wishing to create a change in travel behaviour, is that, primarily, policies and 
strategies are put in place that act as disincentives toward driving. This is recommended since strategies such as increasing density are not likely to result in behaviour changes in outer suburban areas as found in this study. The travel behaviour of outer suburban areas, such as York Region, is largely auto dependent. Strategies that restrict parking supply, or charge for the use of parking, are considered effective ways to alter travel behaviour. These strategies will complement the policies of intensification as well as transit system improvements. It is to be made clear that the findings and recommendations within this study are not to concretely state that increasing the density of outer suburban areas is a consequential strategy. If outer suburban areas like York Region are to become less reliant upon the car, built form needs to be supportive of other modes of transportation such as public transit. This is not possible without increasing density. However, density increases need to be considered carefully as to not increase auto traffic. Other transportation policies need to coexist with intensification policies to ensure a sufficient change in travel behaviour occurs amongst existing residents, as well as to ensure new residents do not become reliant upon the car. 


\section{References}

Cervero, Robert, and Change Deok Kang (2011). "Bus rapid transit impacts on land uses and land values in Seoul, Korea". Transport Policy, 18. pp. 102-116

City of Markham (2014). "City of Markham Parking Standards By-Law 28-97, as amended". Office Consolidation October 21, 2014

D. Levinson; A. Kumar (1994). "The Rational Locator: Why Travel Times Have Remained Stable". JAPA, 60(3), Summer 1994. APA

David Levinson, Yao Wu (2005). "The rational locator re-examined: Are travel times still stable?". Transportation, 32. pp. 187-202

Echenique, Marcial, and Rob Homewood (2003). "The Future of Suburbs and Exurbs". Report for the Independent Transport Commission. University of Cambridge Department of Architecture

Frank, Lawrence, Mark Bradley, Sarah Kavage, James Chapman, and T. Keith Lawton (2008). "Urban form, travel time, and cost relationships with tour complexity and mode choice". Transportation, 35 . pp. 37-54

Frisken, Wallace, Marcia Wallace (2002). "The Response of the Municipal Public Service Sector to the Challenge of Immigrant Settlement". Citizenship and Immigration Canada, Ontario Region, OASIS. pp. 98-143.

Gordon, Peter, and Harry W. Richardson (2000). "Critiquing Sprawl's Critics". Policy Analysis, 365. pp. $1-18$

Jun, Myung-Jin (2008), “Are Portland's Smart Growth Policies Related to Reduced Automobile Dependence?". Journal of Planning Education and Research, 28. pp. 100-107

Lo L., A. Shalaby, B. Alshalalfah (2011). "Relationship between Immigrant Settlement Patterns and Transit Use in the Greater Toronto Area". Journal of Urban Planning and Development, 137. pp. $470-476$

Mees, Paul (1995). "Urban transport policy paradoxes in Australia: A period of smog highlights Melbourne's inadequate public transport”. World Transport Policy \& Practice, 1(1). pp. 20-24

Melia, Steve, Graham Parkhurst, and Hugh Barton (2011). "The paradox of intensification". Transport Policy, 18. pp. 46-52

Millard-Ball, Adam (2002). "Putting on Their Parking Caps". Planning, 68(4). pp. 16-21

Ontario Ministry of Infrastructure (2013). "Growth Plan for the Greater Golden Horseshoe, 2006". Office Consolidation, June 2013

Rye, Tom, and Stephen Ison (2005). "Overcoming barriers to the implementation of car parking charges at UK workplaces". Transport Policy, 12. pp. 57-64 
Schwanen, Tim, Martin Dijst, and Frans M. Dieleman (2004). "Policies for Urban Form and their Impact on Travel: The Netherlands Experience”. Urban Studies, 41(3). pp. 579-603

Shoup, Donald (1995). “An Opportunity to Reduce Minimum Parking Requirements". JAPA, 6(1). pp. 14-28

Statistics Canada (2013). Aurora, T, Ontario (Code 3519046) (table). National Household Survey (NHS) Profile. 2011 National Household Survey. Statistics Canada Catalogue no. 99004-XWE. Ottawa. Released September 11, 2013.

Statistics Canada (2013). East Gwillimbury, T, Ontario (Code 3519054) (table). National Household Survey (NHS) Profile. 2011 National Household Survey. Statistics Canada Catalogue no. 99-004-XWE. Ottawa. Released September 11, 2013.

Statistics Canada (2013) Georgina, T, Ontario (Code 3519070) (table). National Household Survey (NHS) Profile. 2011 National Household Survey. Statistics Canada Catalogue no. 99004-XWE. Ottawa. Released September 11, 2013.

Statistics Canada (2013). King, TP, Ontario (Code 3519049) (table). National Household Survey (NHS) Profile. 2011 National Household Survey. Statistics Canada Catalogue no. 99-004-XWE. Ottawa. Released September 11, 2013.

Statistics Canada (2013). Markham, T, Ontario (Code 3519036) (table). National Household Survey (NHS) Profile. 2011 National Household Survey. Statistics Canada Catalogue no. 99004-XWE. Ottawa. Released September 11, 2013.

Statistics Canada (2013). Newmarket, T, Ontario (Code 3519048) (table). National Household Survey (NHS) Profile. 2011 National Household Survey. Statistics Canada Catalogue no. 99004-XWE. Ottawa. Released September 11, 2013.

Statistics Canada (2013). Richmond Hill, T, Ontario (Code 3519038) (table). National Household Survey (NHS) Profile. 2011 National Household Survey. Statistics Canada Catalogue no. 99-004-XWE. Ottawa. Released September 11, 2013.

Statistics Canada (2013) Toronto, C, Ontario (Code 3520005) (table). National Household Survey (NHS) Profile. 2011 National Household Survey. Statistics Canada Catalogue no. 99004-XWE. Ottawa. Released September 11, 2013.

Statistics Canada (2013). Vaughan, CY, Ontario (Code 3519028) (table). National Household Survey (NHS) Profile. 2011 National Household Survey. Statistics Canada Catalogue no. 99004-XWE. Ottawa. Released September 11, 2013.

Statistics Canada (2013) Whitchurch-Stouffville, T, Ontario (Code 3519044) (table). National Household Survey (NHS) Profile. 2011 National Household Survey. Statistics Canada Catalogue no. 99-004-XWE. Ottawa. Released September 11, 2013.

Statistics Canada (2004). Andrew Heisz and Grant Schellenberg. Public Transit Use Among Immigrants. May 13, 2004 
Susilo, Yusak O., and Kees Maat (2007). "The influence of built environment to the trends in commuting journeys in the Netherlands". Transportation, 34. pp. 589-609

The Corporation of the Town of Newmarket (2013). "Zoning By-Law 2010-40”. Consolidation December 2013

The Corporation of the City of Vaughan (2012). "By-Law Number 1-88". The Comprehensive Zoning By-Law

Urban Strategies Inc. (2013). "The VMC Plan: secondary plan for the Vaughan metropolitan centre".

Vance, Colin, and Ralf Hedel (2007). "The impact of urban form on automobile travel:

disentangling causation from correlation”. Transportation, 34. pp. 575-588

York Region (2012). "York Region Official Plan”. Modified York Region Official Plan - 2010

York Region Transit (2011). "York Region Transit Five Year Service Plan". 